\title{
EL DINERO EN LA ECONOMÍA MODERNA: UNA INTRODUCCIÓN
}

\author{
Michael McLeay \\ Amar Radia \\ Ryland Thomas*
}

$\mathrm{E}^{1}$ dinero es esencial para el funcionamiento de una economía moderna, pero su naturaleza ha variado sustancialmente a través del tiempo. Este artículo es una introducción a lo que hoy es el dinero.

El dinero hoy es un tipo de pagaré, pero un pagaré especial porque en la economía todos confían en que será aceptado por otras personas a cambio de bienes y servicios.

Hay tres tipos principales de dinero: efectivo en circulación, depósitos bancarios y reservas del banco central. Cada tipo representa un pagaré de un sector de la economía a otro. La mayor parte del dinero de la economía moderna está en forma de depósitos bancarios, que son creados por los bancos comerciales.

La mayoría de las personas de todo el mundo usan diariamente alguna forma de dinero para comprar o vender bienes y servicios, para pagar o recibir pagos, o para hacer o saldar contratos. El dinero es esencial para el funcionamiento de una economía moderna. Pero a pesar de su importancia y su uso general, no hay un acuerdo universal sobre qué es realmente el dinero. En parte, porque lo que ha constituido dinero ha variado a través del tiempo y de un lugar a otro.

\footnotetext{
* Los autores son miembros del Directorio de Análisis Monetario del Banco de Inglaterra y agradecen a Lewis Kirkham por su ayuda en la elaboración de este artículo. Tomado de Bank of England, Quarterly Bulletin, 2014, Q1, [http://www.bankofengland.co.uk/publications/Documents/quarterlybulletin/2014/ qb14q1prereleasemoneyintro.pdf]. Traducción de Alberto Supelano; no fue elaborada por el Banco de Inglaterra y no es una traducción oficial del Banco, el cual no se hace responsable de ningún error contenido en ella. Se publica con las autorizaciones correspondientes. Fecha de recepción: 30 de julio de 2015, fecha de aceptación: 29 de octubre de de 2015. Sugerencia de citación: McLeay, M.; A. Radia y R. Thomas. "El dinero en la economía moderna: una introducción", Revista de Economía Institucional 17, 33, 2015, pp. 333-353. DOI: http://dx.doi. org/10.18601/01245996.v17n33.15
} 


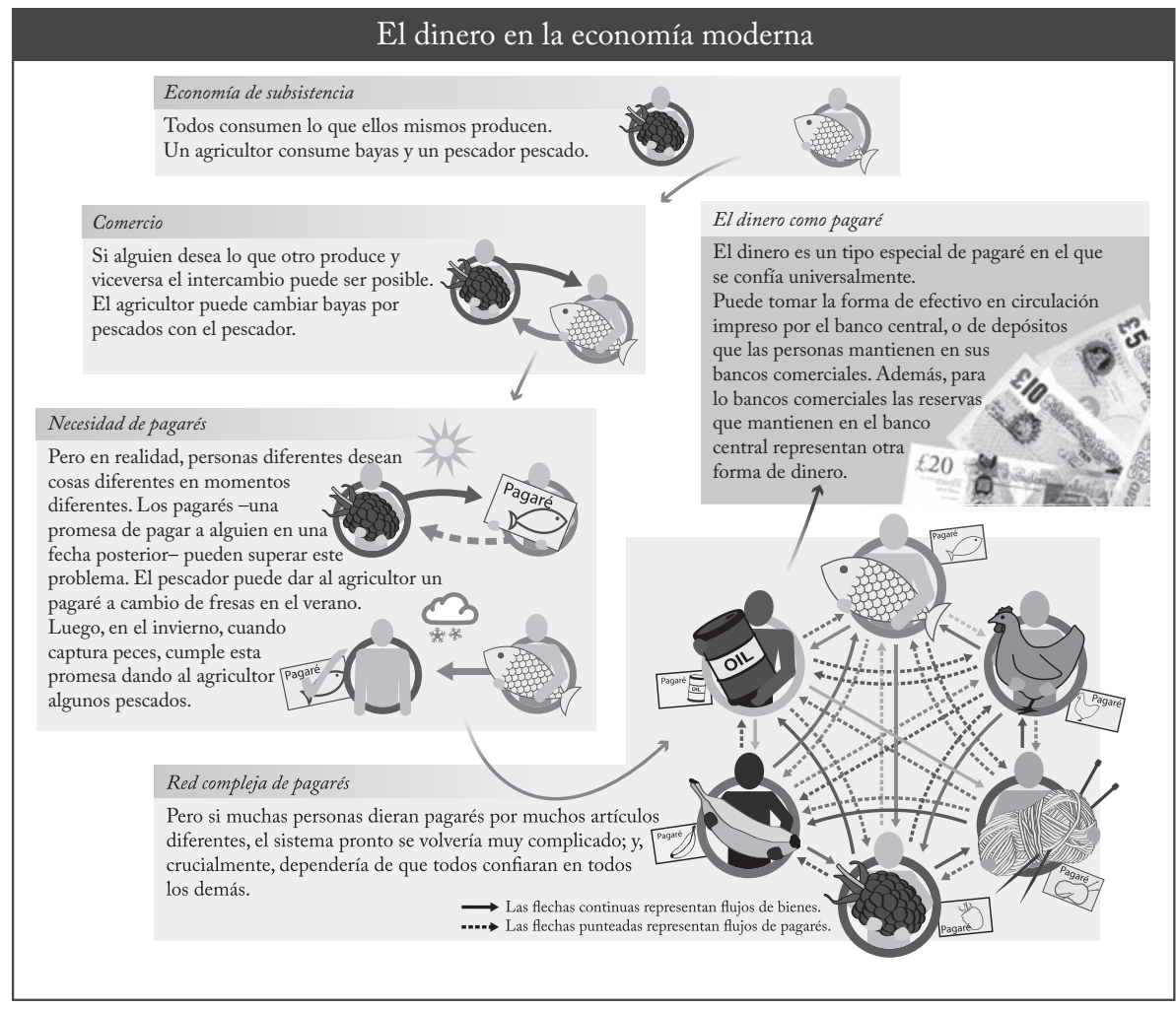

Este artículo es una introducción al papel de dinero en la economía moderna. No supone ningún conocimiento previo de economía para poder leerlo. Empieza explicando el concepto de dinero y lo que lo hace especial. Después plantea qué cuenta como dinero en una economía moderna como el Reino Unido, donde el 97\% del dinero en poder del público está en forma de depósitos bancarios y no como efectivo ${ }^{1}$. Describe los diferentes tipos de dinero, de dónde obtienen su valor y cómo se crean. Un recuadro resume brevemente algunos desarrollos recientes en las tecnologías de pagos. El escrito que acompaña a este artículo, "La creación de dinero en la economía moderna", describe el proceso de creación de dinero en más detalle, y discute el papel de la política monetaria y del banco central en ese proceso. Para fines expositivos este artículo se concentra en el Reino Unido, pero los temas que discute son igualmente relevantes para la mayoría de

1 En diciembre de 2013. En este artículo se usan los términos "bancos" y "bancos comerciales" para referirse a los bancos y las sociedades de construcción en conjunto.

${ }^{2}$ Ver [www.bankofengland.co.uk/publications/Documents/quarterlybulletin/2014/ qb14q1prereleasemoneycreation.pdf]. 
las economías de hoy en día. Un corto video explica algunos de los aspectos esenciales que cubre este artículo ${ }^{3}$.

\section{¿QUÉ CUENTA COMO DINERO?}

En algún momento o en alguna parte se han usado como dinero muchos bienes o activos diferentes. Los bienes son cosas que se valoran porque satisfacen necesidades o deseos de las personas: alimentos, vestuario o libros. Un activo, como la maquinaria, es algo valioso porque se puede usar para producir otros bienes o servicios. ¿De modo que cuáles bienes o activos se deben considerar como dinero? Una manera común de definir el dinero es a través de las funciones que desempeña. Tradicionalmente, este enfoque sugiere que el dinero debe cumplir tres papeles importantes.

El primer papel del dinero es ser depósito de valor; algo que se espera que mantenga su valor en forma razonablemente previsible a través del tiempo. E1 oro o la plata que se extrajeron hace cientos de años son aún valiosos. En cambio, los alimentos perecederos dejan de tener valor cuando se dañan. Por ello, el oro o la plata son buenos depósitos de valor, pero los alimentos perecederos no lo son.

E1 segundo papel del dinero es ser unidad de cuenta; la cosa en que se fijan los precios de los bienes y servicios, por ejemplo, en menús, contratos o etiquetas de precio. En las economías modernas la unidad de cuenta suele ser una moneda, por ejemplo, la libra en el Reino Unido, pero podría ser algún tipo de bien. En el pasado, el precio de los artículos a menudo se fijaba en términos de algo muy común, como bienes alimenticios ("fanegas de trigo") o animales de labranza.

En tercer lugar, el dinero debe ser medio de cambio; algo que las personas mantienen porque piensan intercambiarlo por otra cosa, en vez de desearlo por sí mismo. Por ejemplo, en algunos campos de prisioneros de guerra durante la Segunda Guerra Mundial, los cigarrillos se convirtieron en medio de cambio a falta de dinero ${ }^{4}$. Incluso los no fumadores estaban dispuestos a cambiar cosas por cigarrillos; no porque pensaran fumárselos, sino porque después podían intercambiarlos por lo que desearan.

Estas funciones están estrechamente vinculadas entre sí. Por ejemplo, un activo es menos útil como medio de cambio si mañana no es tan valioso, es decir, si no es un buen depósito de valor. De hecho, en algunos países donde la moneda tradicional se ha convertido en un mal depósito de valor debido a tasas de inflación de precios muy

${ }^{3}$ Ver [www.youtube.com/watch?v=ziTE32hiWdk].

${ }^{4}$ Ver Radford (1945). 
altas, o hiperinflación, las monedas extranjeras se han llegado a usar como medio de cambio alternativo. Por ejemplo, en los cinco años posteriores al final de la Primera Guerra Mundial, los precios de los bienes en marcos alemanes se duplicaron 38 veces; es decir, algo que costaba un marco en 1918 costaba más de 300 mil millones de marcos en $1923^{5}$. Por ello, en esa época en Alemania algunas personas empezaron a utilizar otras monedas en vez de marcos para comprar $y$ vender cosas. Para asegurar que la libra esterlina no pierda su utilidad en el intercambio, uno de objetivos del Banco de Inglaterra es salvaguardar el valor de la moneda. Aunque el medio de cambio debe ser un buen depósito de valor, hay muchos buenos depósitos de valor que no son buenos medios de cambio ${ }^{6}$. Las viviendas, por ejemplo, tienden a seguir siendo valiosas durante largos periodos de tiempo, pero no pueden circular fácilmente como pagos.

De manera similar, es bastante eficiente que el medio de cambio de la economía sea también la unidad de cuenta ${ }^{7}$. Si los almacenes del Reino Unido fijaran el precio de los artículos en dólares y solo aceptaran pagos en libras esterlinas, los clientes tendrían que conocer la tasa de cambio libra esterlina-dólar cada vez que quisieran comprar algo. Esto tomaría tiempo y esfuerzo de los clientes. De modo que en la mayoría de los países los almacenes hoy fijan el precio en términos de la moneda que es el medio de cambio: la libra esterlina en el Reino Unido ${ }^{8}$.

Históricamente, los economistas han considerado que la función más importante del dinero es la de ser medio de cambio 9 .Adam Smith, uno de los padres fundadores de la economía y cuyo retrato figura en el billete de 20 libras, veía el dinero como una parte esencial del paso de una economía de subsistencia, o autarquía, a una economía de intercambio. En una economía de subsistencia, todos consumen únicamente lo que producen. Por ejemplo, Robinson Crusoe, desamparado y solo en una isla desierta, no necesitaba dinero porque solo comía los bayas que recogía y los animales que cazaba ${ }^{10}$. Pero es más eficiente que las personas se especialicen en la producción, produzcan mayores can-

${ }^{5}$ Ver Sargent (1982).

${ }^{6}$ Ver Ostroy y Starr (1990).

7 Brunner y Meltzer (1971) exponen en detalle la forma en que el uso de un activo como unidad de cuenta puede respaldar su uso como medio de cambio.

${ }^{8}$ Esto no siempre ha sido cierto en muchos países, y en algunos lugares aún hoy existen medios de cambio y unidades de cuenta independientes para algunas transacciones. Doepke y Schneider (2013) dan varios ejemplos.

${ }^{9}$ Los orígenes históricos del dinero son tema de arduo debate. Para una discusión, ver el capítulo 1 de Mannig, Nier y Schanz (2009).

${ }^{10}$ Robinson Crusoe fue un personaje ficticio que naufragó en una isla, de una novela del siglo XVIII escrita por Daniel Defoe. 
tidades de un bien que las que necesitan y después comercien entre sí. Si Robinson Crusoe fuera un recolector habilidoso, por ejemplo, podría centrar su esfuerzo en recoger bayas mientras que su amigo Viernes, pescador experto, podría dedicar todo su tiempo a la pesca. Los dos podrían entonces intercambiar entre sí y consumir más bayas y pescados que si cada cual repartiera su tiempo entre recoger bayas y atrapar pescados ${ }^{11}$.

\section{EL DINERO ES UN PAGARÉ}

Aunque Robinson Crusoe y Viernes podían intercambiar simplemente bayas por pescados - sin usar dinero-, los intercambios que las personas desean realizar en la economía moderna son mucho más complicados. Interviene un gran número de personas ${ }^{12}$. Y, lo que es crucial, el momento de esos intercambios normalmente no coincide. Así como las personas no siempre desean consumir el mismo tipo de bienes que ellas han producido, no siempre desean consumirlos en el mismo momento en que los producen. Robinson Crusoe puede recoger una gran cantidad de bayas durante el verano, cuando están en estación, mientras que Viernes solo puede atrapar muchos peces en el otoño. En la economía moderna, los jóvenes desean endeudarse para comprar vivienda, las personas mayores ahorrar para la jubilación y los trabajadores prefieren gastar su salario mensual gradualmente a lo largo del mes, en vez de gastarlo todo el día de pago. Estos patrones de demanda indican que algunas personas desean endeudarse y otras mantener notas promisorias -o pagarés- que alguna otra debe pagar en un momento posterior. En la economía moderna el dinero es simplemente una forma especial de pagaré o, en el lenguaje de las cuentas económicas, un activo financiero.

Para entender el dinero como activo financiero es conveniente considerar primero la gran variedad de tipos de activos que mantienen las personas (individualmente o como compañías). Algunos de ellos se muestran en la gráfica 1. Los activos no financieros, como el capital (p. ej., maquinaria), la tierra y las viviendas se presentan en color gris claro. Cada activo no financiero puede producir bienes y servicios a sus propietarios. Por ejemplo, la maquinaria y la tierra se pueden usar para elaborar productos o alimentos, las viviendas prestan

${ }^{11}$ Smith (1766) señaló que "en una nación de cazadores, si alguien tiene más talento para hacer arcos y flechas que sus vecinos primero tendrá que regalárselos y a cambio después le regalarán piezas de caza”.

12 Como señaló Smith (1776), "cuando se empezó a practicar la división del trabajo, esta capacidad de cambio muchas veces se vio entorpecida y obstaculizada en sus operaciones. 
el servicio de abrigo y comodidad, y al oro se le pueden dar formas que las personas desean, como joyas.

Es posible que algunos de estos activos no financieros (o incluso los bienes que producen) cumplan algunas de las funciones del dinero. Cuando los bienes o activos que son valiosos para otros propósitos se utilizan como dinero, se conocen como dinero mercancía. Por ejemplo, Adam Smith señaló que "el hierro fue el instrumento común de comercio entre los espartanos antiguos" y "el cobre entre los romanos antiguos"13. Muchas sociedades también han usado oro como dinero mercancía. El uso como dinero de mercancías que son valiosas en sí mismas puede ayudar a que las personas confíen en que podrán intercambiarlas por otros bienes en el futuro. Pero como estas mercancías tienen otros usos - p. ej., en la construcción o en joyería-, usarlas como dinero tiene un costo ${ }^{14}$. De modo que en la economía moderna el dinero es, en cambio, un activo financiero.

Gráfica 1

El dinero y otros activos y obligaciones ${ }^{(a)}$

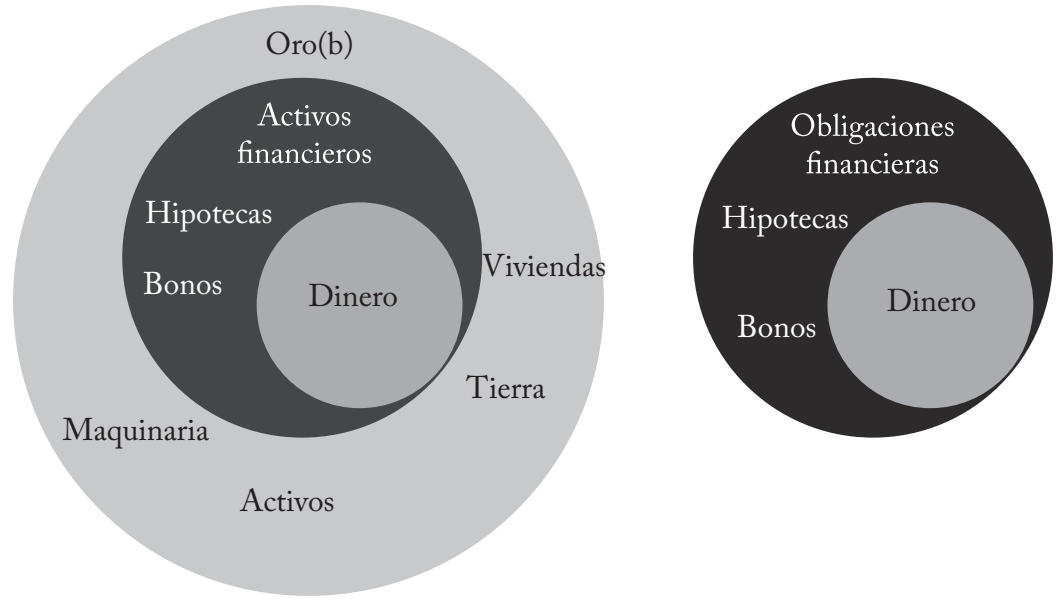

(a) La gráfica es sumamente estilizada para facilitar la exposición: las cantidades de cada activo/ obligación que se muestran no concuerdan con sus cantidades reales en la economía.

(b) Por convención estadística, en las cuentas económicas algunas tenencias de oro (como las del gobierno) se clasifican como activo financiero y no como activo no financiero.

Los activos financieros son simplemente obligaciones de algún participante en la economía: un pagaré a una persona, compañía, banco o gobierno. Un activo financiero puede ser creado por propietarios

${ }^{13}$ Smith (1776).

${ }^{14}$ La siguiente sección discute otras desventajas de usar mercancías como dinero o vincular el dinero a mercancías. 
de activos no financieros. Por ejemplo, un hacendado puede arrendar parte de su tierra a un agricultor a cambio de parte de la cosecha futura. E1 hacendado tiene menos tierra que antes, pero a cambio tiene un activo financiero: un derecho sobre bienes futuros (alimentos) que produzca el agricultor que usa el activo (tierra). En realidad, sin embargo, la mayoría de los activos financieros son derechos sobre otros activos financieros. La mayoría de las personas que consideran comprar un bono de una compañía (un tipo de pagaré de la compañía al tenedor del bono), como una granja agrícola, no desean que se les pague con alimentos. En vez de ello, los contratos de bonos usualmente estipulan que al tenedor del bono se le debe cierta suma de dinero, que la granja puede obtener vendiendo sus alimentos.

Debido a que los activos financieros son exigencias de pago a otro participante en la economia, son también obligaciones financieras; el activo financiero de una persona es siempre una deuda de otra persona. Así, en una economía cerrada el tamaño de las obligaciones financieras es igual al tamaño de los activos financieros, como se muestra en la gráfica $1^{15}$. Si una persona contrae una deuda hipotecaria, adquiere la obligación de pagar a su banco una suma de dinero a través del tiempo -una obligación-, y el banco adquiere el derecho a recibir esos pagos -un activo del mismo tamaño- ${ }^{16}$. O si posee bonos de una compañía, tiene un activo y la compañía tiene una obligación de igual tamaño. En cambio, los activos no financieros no son demandas de pago a algún otro. Si alguien posee una vivienda u oro, no hay una persona correspondiente que deba esa cantidad; de modo que no son obligaciones financieras. Si todos los participantes en la economía reunieran todos sus activos y sus deudas en un fondo único, todos los activos financieros y las obligaciones -incluido el dinero- se cancelarían, y solo quedarían los activos no financieros.

\section{POR QUÉ EL DINERO ES ESPECIAL}

En principio, podría no haber necesidad de un activo financiero especial como el dinero para registrar a quién se deben bienes y servicios. Todos podrían en cambio crear sus propios activos y obligaciones financieros entregando pagarés cada vez que quisieran

\footnotetext{
15 Una economía cerrada, como la isla desierta de Robinson Crusoe, es una economía que no realiza ningún intercambio con economías externas.

${ }^{16}$ La suma que el deudor hipotecario debe pagar a través del tiempo normalmente será mayor que el monto original de la deuda, porque los prestatarios usualmente deben pagar intereses sobre sus obligaciones para compensar al prestamista por la inconveniencia de mantener un pagaré que solo se reembolsará en una fecha posterior.
} 
comprar algo, y luego asentar en un libro mayor si tienen deudas o créditos en el total de pagarés. De hecho, en la Europa medieval los comerciantes solían tratar entre sí emitiendo pagarés. Y las casas comerciales saldaban periódicamente las demandas de pago mutuas en las ferias, cancelando las deudas ${ }^{17}$. Pero esos sistemas se basan en que todos crean que los demás son totalmente confiables ${ }^{18}$. De otro modo, la gente se preocuparía porque algunos de los pagarés que mantiene sean emitidos por personas que no los pagan cuando acude a redimirlos. Aunque confíe en todas aquellas a las que ha prestado directamente, podría preocuparse por aquellas que mantienen pagarés de personas no fiables y, por tanto, no podrían reembolsar sus propios pagarés.

El dinero es una institución social que da una solución al problema de la falta de confianza ${ }^{19}$. Es útil en el intercambio porque es una clase especial de pagaré: en particular, en la economía moderna el dinero es un pagaré en el que todos confían. Debido a que todos confían en el dinero, son felices de aceptarlo a cambio de bienes y servicios; y puede llegar a ser universalmente aceptable como medio de cambio. Solo ciertos tipos de pagarés pueden obtener ese estatus. Por ejemplo, si no se confía ampliamente en que se reembolsará un tipo de pagaré, es menos probable que sea aceptable en el intercambio, y menos como dinero. La siguiente sección explica qué tipos de pagarés funcionan como dinero en la economía moderna, y cómo se llegó a tener suficiente confianza en esos pagarés particulares para que fuesen universalmente aceptables en el intercambio.

\section{DIFERENTES TIPOS DE DINERO}

En la sección anterior se explicó que si bien muchos bienes o activos pueden cumplir algunas de las funciones del dinero, hoy el dinero es un tipo especial de pagaré. Para entenderlo aún más, es útil considerar algunos de los diferentes tipos de dinero que circulan en una economía moderna; cada tipo representa pagarés entre diferentes

${ }^{17}$ Las ferias medievales y su importancia económica se discuten en más detalle en Braudel (1982).

${ }^{18} \mathrm{La}$ importancia de la falta de confianza como condición necesaria para la existencia del dinero se subraya en los trabajos de Kiyotaki y Moore (2001,2002), quienes argumentan que "la maldad es el origen de todo dinero". Kocherlakota (1998) plantea que la falta de un registro de todas las transacciones es otra condición necesaria. Brunner y Meltzer (1971) y Rey y Plosser (1986) también argumentan que debe haber algún obstáculo para dejar que un sistema de crédito se use en vez del dinero.

${ }^{19}$ King (2006) presenta una explicación detallada del dinero como institución social. 
grupos de personas. Todos estos tipos de dinero, junto con otros términos que se usan comúnmente en relación con el dinero, se presentan en un glosario (cuadro A) al final del artículo. Para este artículo, la economía se divide en tres grupos principales: el banco central (en el Reino Unido, el Banco de Inglaterra), los bancos comerciales (p. ej., bancos como Barclays y Lloyds) y el sector privado restante de hogares y compañías, al que en adelante se denomina "consumidores".

Los analistas económicos y los académicos suelen prestar mucha atención a la cantidad de "dinero en sentido amplio" que circula en la economía. Este se puede considerar como el dinero de que disponen los consumidores para transacciones, y comprende: efectivo en circulación (billetes y monedas), un pagaré del banco central, principalmente a los consumidores; y depósitos bancarios: un pagaré de los bancos comerciales a los consumidores ${ }^{20}$. El dinero en sentido amplio es un concepto útil porque mide la cantidad de dinero que mantienen los responsables de las decisiones de gasto: los hogares y las compañías. Un recuadro del artículo que acompaña a este explica qué información acerca de la economía pueden revelar las diferentes medidas del dinero.

Una definición diferente del dinero, a menudo llamada "base monetaria" o "dinero del banco central", comprende los pagarés del banco central: estos incluyen el efectivo en circulación (un pagaré a los consumidores) y también las reservas depositadas en el banco central, que son pagarés del banco central a los bancos comerciales. La base monetaria es importante porque es en virtud de su posición como emisor único de la base monetaria que los bancos centrales pueden implementar la política monetaria ${ }^{21}$. El artículo acompañante explica de qué modo el Banco de Inglaterra varía la tasa de interés que paga a las reservas para afectar el gasto y la inflación, junto con las cantidades de los diferentes tipos de dinero.

${ }^{20}$ La definición del dinero en sentido amplio que usa el Banco de Inglaterra, M4 $4^{\text {ex }}$ incluye una gama de obligaciones del banco más amplia que los depósitos regulares; para más detalles, ver Burgess y Janssen (2007). Por simplicidad, este artículo describe todas esas obligaciones como depósitos.

${ }^{21}$ También se permite que algunos bancos comerciales de Escocia e Irlanda del Norte emitan sus propios billetes, pero para hacerlo también deben mantener una cantidad igual de billetes del Banco de Inglaterra o de reservas depositadas en el Banco de Inglaterra, lo que significa que su emisión no altera el monto de la base monetaria. Los billetes que mantienen en el Banco pueden incluir billetes de 1 millón de libras (Gigantes) y de 100 millones (Titanes). 


\section{Gráfica 2}

Balances estilizados de diferentes tipos de tenedores y emisores de dinero ${ }^{(a)}$

Banco central(b)

Activos Obligaciones

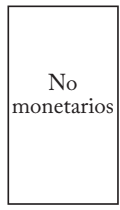

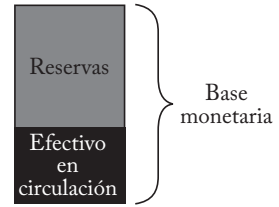

Bancos comerciales(c)

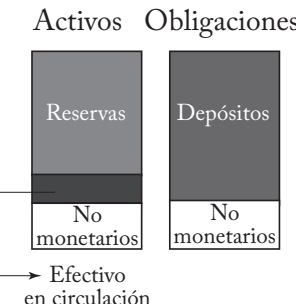

Consumidores $(\mathrm{d})$

Activos Obligaciones

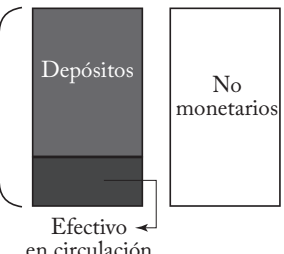

(a) Los balances son muy estilizados para facilitar la exposición: las cantidades de cada tipo de dinero que se muestran no corresponden a las cantidades que realmente se mantienen en el balance de cada sector.

(b) E1 balance del banco central solo muestra las obligaciones y los activos correspondientes de la base monetaria. En la práctica, el banco central mantiene otras obligaciones no monetarias. Sus activos no monetarios son en su mayoría deuda del gobierno. Aunque la deuda del gobierno es mantenida por el Fondo de Compra de Activos del Banco de Inglaterra, de modo que no aparece directamente en el balance consolidado del Banco.

(c) Los activos no monetarios de los bancos comerciales incluyen deuda del gobierno y las obligaciones no monetarias incluyen deuda de largo plazo y acciones.

(d) Los consumidores representan el sector privado de hogares y empresas. El balance solo muestra los activos de dinero en sentido amplio y las obligaciones correspondientes. Las obligaciones no monetarias de los consumidores incluyen préstamos asegurados y no asegurados.

\section{¿QUUIÉN DEBE A QUIÉN? DESCRIPCIÓN DE LOS PAGARÉS}

Dibujar un balance es un medio útil para representar los pagarés mutuos de las diferentes personas. Como ya se discutió, todo pagaré es una obligación financiera de una persona, asociada a un activo financiero de alguna otra. Por tanto, para una individuo, su balance simplemente suma en conjunto, por un lado, todos sus activos: sus pagarés de otras personas y sus activos no financieros; $y$, por otro lado, todas sus obligaciones (o deudas): sus pagarés $a$ otras personas ${ }^{22}$.

Se puede sumar a los individuos de cada grupo para obtener un balance consolidado, el cual muestra los pagarés de ese grupo a los demás grupos de la economía ${ }^{23}$. La gráfica 2 muestra un balance estilizado de activos y obligaciones de cada uno de los tres grupos de la economía. Los diferentes tipos de dinero se representan con un color diferente: el efectivo en circulación en negro, los depósitos bancarios en gris oscuro y las reservas depositadas en el banco central en gris

${ }^{22}$ Por convención, el total de activos y obligaciones se debe balancear. Si los activos son mayores que la deuda, la diferencia se define como capital propio del tenedor de activos. Por ejemplo, un consumidor sin deuda tendría un capital igual al valor de sus activos. Para una introducción al capital en el contexto bancario, ver Farag et al. (2013).

${ }^{23}$ Las deudas con otros individuos del grupo se cancelan, dejando únicamente pagarés a y de otros grupos. 
claro. Por consiguiente, el dinero en sentido amplio está representado por la suma de activos negros y grises oscuros que mantienen los consumidores, mientras que la base monetaria es la suma de todos los activos negros y grises claros. (Nótese que los balances no se dibujan a escala; en realidad, la cantidad de dinero en sentido amplio es mayor que el monto de la base monetaria.) Cada tipo de dinero representa los balances de al menos dos grupos diferentes, porque cada cual es un activo de un grupo y una obligación de otro. Existen también muchos otros activos y obligaciones que no cumplen las funciones del dinero (todos excepto los círculos en negro de la gráfica 1); algunos de ellos se muestran en blanco en la gráfica 2. Por ejemplo, los consumidores mantienen préstamos tales como las hipotecas, que son obligaciones del consumidor y activos del banco del consumidor.

E1 resto de esta sección analiza en más detalle cada uno de los tres tipos de dinero, explica por qué es valioso y describe brevemente cómo se $\mathrm{crea}^{24}$. E1 recuadro de la página 12 esboza algunos desarrollos recientes de las tecnologías de pago y las monedas alternativas que han llevado a crear diferentes instrumentos que tienen algunas similitudes con el dinero.

\section{(I) DINERO FIDUCIARIO; BILLETES Y MONEDAS}

\section{¿̇Qué es?}

E1 efectivo en circulación está formado sobre todo por billetes (cerca del 94\% del valor total en diciembre de 2013), que en su mayoría son un pagaré del Banco de Inglaterra al resto de la economía ${ }^{25}$. La mayor parte del efectivo en circulación está en manos de los consumidores, aunque los bancos comerciales también mantienen pequeñas cantidades para satisfacer retiros de depósitos. Como se indica en su inscripción, los billetes son una "promesa de pago" al tenedor del billete, a la vista, de una suma especificada (p. ej., 5 libras). Esto hace de los billetes una obligación del Banco de Inglaterra y un activo de sus tenedores, que se muestra en negro en sus balances en la gráfica 2.

Cuando el Banco de Inglaterra se fundó en 1694, sus primeros billetes eran convertibles en oro. El proceso de emisión de "notas" convertibles en oro empezó antes, cuando los banqueros-joyeros empezaron a almacenar monedas de oro de los clientes. Los joyeros

${ }^{24}$ Ryan-Collins et al. (2011) presentan una detallada explicación introductoria de dónde proviene el dinero.

${ }^{25}$ Cerca del 6\% restante del dinero en circulación está formado por monedas, que se producen en la Casa de Acuñación Real. De los billetes que circulan en la economía del Reino Unido, algunos son emitidos por ciertos bancos comerciales de Escocia e Irlanda del Norte. 


\section{Desarrollos recientes en las tecnologías de pago y monedas alternativas}

E1 pasado reciente ha visto una oleada de innovaciones en tecnologías de pago y monedas alternativas. Este recuadro esboza algunos de esos desarrollos y muestra cómo se relacionan con el concepto de dinero que se discute en el texto principal. Aunque en general desempeñan -en diverso grado- algunas funciones del dinero, hoy no son normalmente aceptadas como medio de cambio en la misma medida que el efectivo en circulación, las reservas del banco central o los depósitos bancarios.

Un conjunto de innovaciones permite que los hogares y empresas conviertan depósitos bancarios en otras formas de dinero puramente electrónicas (a veces llamadas "dinero electrónico") que se pueden usar para hacer transacciones. Estas tecnologías buscan mejorar el proceso de pagos. Por ejemplo, PayPal y Google Wallet. Así como puede ser más conveniente hacer transacciones usando depósitos bancarios en vez de billetes, para algunas transacciones también puede ser más conveniente usar dinero de una cuenta electrónica en vez de billetes o depósitos bancarios. Estas formas de dinero tienen algunas características similares a los depósitos bancarios. Por ejemplo, el dinero en una cuenta de dinero electrónico representa un depósito de valor siempre que las compañías proveedoras se consideren confiables. El dinero electrónico también se puede utilizar como medio de cambio con empresas (como las vendedoras en línea) o individuos que lo acepten. Pero no es aún tan ampliamente aceptado como otros medios de cambio, por ejemplo, no es aceptado en las ventas callejeras. Las transacciones que usan estas tecnologías también suelen estar denominadas en la unidad de cuenta existente (libras esterlinas en el Reino Unido).

Otro conjunto de innovaciones ha servido para introducir una nueva unidad de cuenta. Estos esquemas buscan promover la actividad económica en un ambiente definido e incluyen monedas locales, como libras Bristol, Brixton o Lewes en el Reino Unido*. Las monedas locales se analizan en detalle en Naqvi y Southgate (2013). Estas formas de dinero se pueden obtener a cambio de moneda circulante a tasas fijas: por ejemplo, una libra esterlina por una libra Bristol. La moneda local luego se puede intercambiar por bienes y servicios cuyo precio se fija en su propia unidad de cuenta; libras Brixton en vez de libras esterlinas. En consecuencia, su uso como medio de cambio es intencionalmente limitado. Por ejemplo, la libra Lewes solo se puede usar en los comercios participantes, que deben estar ubicados en el área de Lewes.

Una clase adicional de innovaciones son las monedas digitales, como Bitcoin, Litecoin y Ripple. La diferencia clave entre estas y las monedas locales es que la tasa de cambio entre monedas digitales y otras monedas no es fija. Hoy las monedas digitales no se usan ampliamente como medio de cambio. Pero su popularidad obedece principalmente a su capacidad para servir como una clase de activo. Como tal, pueden tener más semejanzas conceptuales con mercancías como el oro que con el dinero. También difieren de las demás tecnologías discutidas hasta ahora en este recuadro porque se pueden crear de la nada, aunque a tasas predeterminadas. En contraste, las monedas locales solo entran en circulación cuando se cambian por libras esterlinas. Mientras que la cantidad de dinero que se mantiene en cuentas electrónicas o en monedas locales depende totalmente de la demanda, la oferta de monedas digitales es típicamente limitada.

* Aunque las monedas locales, o complementarias, no son una innovación reciente, solo hasta hace poco se han adoptado en algunas zonas del Reino Unido. Para más detalles, ver Naqvi y Southgate (2013). 
daban recibos por las monedas, y esos recibos pronto empezaron a circular como un tipo de dinero. El Banco de Inglaterra intercambiaría oro por sus billetes de un modo similar; siempre dispuesto a cambiar sus notas por oro a la vista. Aparte de algunos breves periodos, así fue como funcionó el dinero durante la mayoría de los 250 años siguientes, con el "patrón oro" ${ }^{26}$. Pero el Banco abandonó permanentemente el ofrecimiento de oro a cambio de billetes en 1931 para que Gran Bretaña pudiera manejar mejor su economía durante la Gran Depresión, como se discute más adelante.

Desde 1931, el dinero del Banco de Inglaterra ha sido dinero fiduciario. El dinero fiduciario o "papel" moneda es dinero no convertible en ningún otro activo (como el oro u otras mercancías).

Debido a que el dinero fiduciario es aceptado como medio de cambio por todos los participantes en la economía, aunque el Banco de Inglaterra esté en deuda con el tenedor de su moneda, esa deuda solo se puede reembolsar en dinero fiduciario. E1 Banco de Inglaterra promete honrar su deuda intercambiando billetes, incluidos aquellos que ya no se usan, por otros del mismo valor para siempre. Por ejemplo, aun después de su retiro el 30 de abril de 2014, el Banco seguirá cambiando el billete de 50 libras con el retrato de Sir John Houblon por el nuevo billete de 50 libras, con los retratos de Matthew Boulton y James Watt.

\section{¿Por qué lo usan las personas?}

E1 dinero fiduciario ofrece ventajas sobre el dinero ligado al oro cuando se trata de manejar la economía. Con dinero fiduciario, las variaciones de la demanda de dinero por el público se pueden afrontar con variaciones en la cantidad de dinero disponible para el público. Cuando la cantidad de dinero está ligada a una mercancía, como el oro, esto impone un límite a la cantidad de dinero que puede existir, pues hay un límite a la cantidad de oro que se puede extraer. $Y$ ese límite a menudo no es apropiado para el buen funcionamiento de la economía ${ }^{27}$. Por ejemplo, el abandono del patrón oro en 1931 permitió que Gran Bretaña recobrara un mayor control de la cantidad de dinero en la economía. El Reino Unido pudo reducir el valor de su

${ }^{26}$ Hubo algunos periodos, en particular durante las guerras, en que el Banco dejó temporalmente de cambiar billetes por oro. La Tesorería también emitió notas cuando estalló la Primera Guerra Mundial; estas “notas del Tesoro” se podían convertir en monedas y se mantuvieron en circulación hasta 1928.

27 También puede haber mucha creación de dinero en periodos en que la cantidad de esa mercancía crece rápidamente. En el siglo XVI, España experimentó un largo periodo de alta inflación después de importar enormes cantidades de oro y plata de América. 
moneda con respecto a otros países que todavía vinculaban su moneda al oro (y esto fue acompañado de una mayor cantidad de dinero en circulación), lo que según algunos historiadores económicos ayudó a que Gran Bretaña no enfrentara una recesión tan profunda como la que enfrentaron muchos otros países en la década de $1930^{28}$.

Aunque el uso de dinero fiduciario tiene ventajas para la economía como un todo, estas no se pueden realizar salvo que los individuos decidan que quieren usarlo en el intercambio. $\mathrm{Y}$, si los billetes no son directamente convertibles en un bien real de algún tipo, ¿qué los hace universalmente aceptables en el intercambio? Una respuesta es que el medio de cambio confiable solo surge en el tiempo como resultado de una convención social o histórica. Hay muchas de esas convenciones que aparecen en la sociedad. Por ejemplo, en el Reino Unido los automovilistas conducen por el lado izquierdo de la vía, y esta convención empezó cuando suficientes conductores cobraron confianza en que la mayoría de los demás haría lo mismo ${ }^{29}$. Pero igualmente la convención pudo haber sido conducir por la derecha, como se hizo en muchos otros países.

En el caso del dinero, sin embargo, en general el Estado ha cumplido un papel en su evolución ${ }^{30}$. Para que sea cómodo mantener efectivo, las personas deben saber que en algún momento alguien está dispuesto a cambiar esos billetes por un bien real o un servicio, lo que el Estado puede ayudar a garantizar. Una manera de hacerlo es asegurar que siempre habrá demanda de la moneda aceptándola como pago de impuestos. El gobierno también puede influir algo en esa demanda considerando que la moneda es "de curso legal"31.

Aunque el Estado apoye de este modo el uso de la moneda, eso por sí solo no asegura que las personas lo usen (o estén obligadas a usarlo). También deben confiar en que sus billetes son valiosos, lo

${ }^{28}$ Temin (1989) y Eichengreen (1992) hacen un detallado análisis del desempeño económico de los países bajo el patrón oro y durante la Gran Depresión.

${ }^{29}$ Young (1998) explica que estas convenciones se formaron en Europa cuando las personas aún conducían carruajes tirados por caballos, en vez de autos. Después fueron consagradas por la ley, garantizando que las personas siguieran la convención.

${ }^{30}$ Goodhart (1998) argumenta que la evidencia histórica sugiere que el Estado fue crucial en el desarrollo del dinero como medio de cambio. Él contrasta esa opinión con la posición de Menger (1892), quien propone una evolución más natural.

${ }^{31}$ Por ejemplo, los billetes del Banco de Inglaterra son las únicas notas de curso legal en Inglaterra y Gales. Pero ese estatus de curso legal solo tiene un significado estrecho relacionado con el pago de deudas. En transacciones ordinarias tiene poca aplicación práctica, puesto que en uso de una moneda como medio de cambio depende únicamente de que haya acuerdo entre las dos partes que realizan el intercambio. 
que quiere decir que es importante que sean difíciles de falsificar ${ }^{32}$. También deben tener fe en que el valor de sus billetes se mantendrá en general estable a través del tiempo para que los mantengan como depósito de valor y puedan usarlos como medio de cambio. Esto significa, en general, que el Estado debe asegurar una tasa de inflación baja y estable.

Desde el abandono del patrón oro en 1931 se han probado otras formas de mantener estable el valor del dinero, con diferentes grados de éxito. Por ejemplo, en la década de 1980, la política buscó mantener la tasa a la que la cantidad de dinero en sentido amplio tuviera un crecimiento estable en el tiempo ${ }^{33}$. Desde 1992, el Banco ha tenido una meta de inflación de precios al consumidor. La meta de inflación significa que el Banco está comprometido a tratar de mantener relativamente estable el valor del dinero en términos de los numerosos bienes y servicios que puede comprar. Así, en vez de confiar en que sus billetes valdrán cierta cantidad de oro, las personas pueden esperar que valdrán una cantidad estable de productos reales entre un año y el siguiente.

\section{¿Cómo se crea?}

E1 Banco de Inglaterra garantiza que crea suficientes billetes bancarios para satisfacer la demanda del público. E1 Banco primero dispone la impresión de billetes nuevos por una impresora comercial. Luego los canjea con los bancos comerciales por billetes viejos; los que ya no son aptos para ser usados o son parte de una serie que ha sido retirada. Estos billetes viejos después son destruidos por el Banco.

La demanda de billetes bancarios también ha aumentado en general a través del tiempo. Para satisfacer esa demanda adicional, el Banco también emite más billetes que los que se necesitan para remplazar billetes viejos ${ }^{34}$. Los billetes nuevos recién emitidos son comprados por los bancos comerciales al Banco de Inglaterra. Por la nueva moneda, un pagaré de papel del Banco de Inglaterra, los bancos comerciales le pagan canjeándolo por alguno de sus otros pagarés electrónicos del Banco: reservas del banco central. El tamaño de sus

\footnotetext{
32 Para mayor información sobre las características actuales de seguridad y materiales de educación, ver [www.bankofengland.co.uk/banknotes/Pages/educational.aspx].

${ }^{33}$ Para historias detalladas de los regímenes de política monetaria en el Reino Unido, ver Cairncross (1995) o Wood (2005).

${ }^{34}$ Para una descripción completa del Esquema de Circulación de Billetes, ver Allen y Dent (2010).
} 
balances en la gráfica 2 no se altera, pero sí cambia la división entre los componente gris claro y negro ${ }^{35}$.

\section{(II) DEPÓSITOS BANCARIOS}

\section{¿Qué son?}

El efectivo en circulación solo representa una muy pequeña cantidad del dinero que mantienen las personas y frmas de la economía. El resto consiste en depósitos bancarios, como muestra la gráfica 1. Por razones de seguridad, los consumidores en general no desean almacenar todo sus activos como billetes físicos. Además, el efectivo en circulación no paga interés, y por esto es menos atractivo de mantener que otros activos, como los depósitos bancarios. Por estas razones, la mayoría de los consumidores prefiere mantener un medio de cambio alternativo: los depósitos bancarios que se muestran en gris oscuro en la gráfica 2. Los depósitos bancarios pueden tomar muchas formas diferentes, por ejemplo, cuentas corrientes o cuentas de ahorros de los consumidores o algunos tipos de bonos bancarios que compran los inversionistas. En la economía moderna estos tienden a ser registrados electrónicamente. Por simplicidad, este artículo se centra en los depósitos bancarios de los hogares y las firmas, pues estos funcionen claramente como dinero.

\section{¿̇or qué los usan las personas?}

Cuando un consumidor deposita sus billetes en un banco, simplemente canjea un pagaré del Banco de Inglaterra por un pagaré del banco comercial. E1 banco comercial consigue billetes adicionales pero a cambio acredita la cantidad depositada en la cuenta del consumidor. Los consumidores solo canjean su dinero por depósitos bancarios porque confían en que siempre podrán ser reembolsados. Los bancos necesitan entonces asegurar que siempre pueden obtener suficientes cantidades de efectivo para satisfacer la demanda esperada de los depositantes y reembolsar sus pagarés. Para muchos hogares depositantes, estos depósitos están garantizados hasta cierto valor, para asegurar que los clientes sigan confiando en ellos ${ }^{36}$. Esto asegura que

35 Como se muestra en la gráfica 2, el efectivo en circulación del Banco de Inglaterra se empareja en el otro lado del balance del banco central con los activos no monetarios, que en tiempos normales son típicamente instrumentos del mercado de libras esterlinas o bonos del gobierno. Estos activos pagan interés, mientras que el efectivo no los paga. El ingreso de esos activos (después de deducir los costos de emisión de billetes del Banco) se paga a la Tesorería, y se conoce como "señoreaje".

${ }^{36}$ El Esquema de Compensación de Servicios Financieros ofrece protección de depósitos pequeños hasta 85.000 libras por depositante de la institución 
se confíe en que los depósitos bancarios son fácilmente convertibles en efectivo y que pueden actuar como medio de cambio en su lugar.

\section{Diagrama 1}

Cantidades de dinero en circulación ${ }^{(a)}$

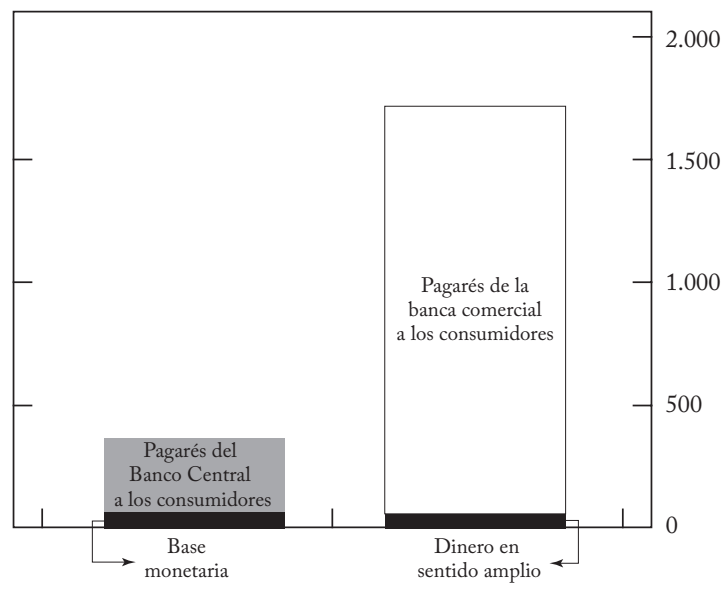

Depósitos bancarios: pagarés de la banca comercial a los consumidores

Reservas: pagarés del banco central a los bancos comerciales ${ }^{(b)}$

Efectivo en circulación: pagarés del Banco Central a los consumidores ${ }^{(\mathrm{c})}$ (d)
(a) Todos los datos corresponden a diciembre de 2013.
(b) Saldos de reservas en el Banco de Inglaterra mantenidos por los bancos y sociedades de construcción ${ }^{37}$, no ajustados estacionalmente. Los datos se miden como el promedio mensual de los datos semanales.
(c) El efectivo en circulación de la base monetaria incluye billetes y monedas en circulación fuera del Banco de Inglaterra, incluidos los de las cajas de los bancos y sociedades de construcción. Los datos se miden como el promedio mensual de los datos semanales.
(d) E1 dinero en sentido amplio solo incluye billetes y monedas en poder del sector privado no bancario, medidos como la posición al final de mes.
(e) M4 excluyendo intermediarios diferentes de las corporaciones financieras.

En la economía moderna, los depósitos bancarios son a menudo el tipo predeterminado de dinero. Muchas personas ahora reciben el pago de su salario en depósitos bancarios y no en efectivo. $Y$ en vez de volver a cambiar esos depósitos por efectivo, muchos consumidores los usan como depósito de valor y cada vez más como medio de cambio. Por ejemplo, cuando un consumidor paga a una tienda con una tarjeta débito, el sector bancario reduce la cantidad que le debe a ese consumidor-los depósitos del consumidor se reducen- mientras que aumenta la cantidad que le debe a la tienda -los depósitos de la

autorizada, la Autoridad de Regulación Prudencial. Para más información, ver [www.fscs.org.uk].

37 En Inglaterra, las sociedades de construcción son entidades financieras de carácter mutual que ofrecen servicios bancarios y financieros, en especial depósitos de ahorro y préstamos hipotecarios [N. del T.]. 
tienda se incrementan-. E1 consumidor ha usado directamente los depósitos como medio de cambio sin tener que convertirlos en efectivo.

\section{¿Cómo se crean?}

A diferencia del efectivo en circulación, que es creado por el Banco de Inglaterra, los depósitos bancarios son creados principalmente por los mismos bancos comerciales. Aunque el volumen de depósitos bancarios aumenta cada vez que alguien deposita billetes en su cuenta, la cantidad de depósitos bancarios también se reduce siempre que alguien hace un retiro. Además, como muestra el diagrama 1, la cantidad de efectivo en circulación es muy pequeña en comparación con el monto de depósitos bancarios. Mucho más importante para la creación de depósitos bancarios es el acto de hacer nuevos préstamos bancarios. Cuando un banco hace un préstamo a uno de sus clientes simplemente acredita un saldo de depósitos más alto en la cuenta del cliente. En ese instante se crea dinero nuevo.

Los bancos pueden crear dinero nuevo porque los depósitos bancarios son simplemente pagarés del banco; la capacidad de los bancos para crear pagarés no es diferente a la de ningún otro en la economía. Cuando el banco hace un préstamo, el prestatario también ha creado un pagaré suyo al banco. La única diferencia es que por las razones que se discutieron antes, el pagaré del banco (el depósito) es ampliamente aceptado como medio de cambio; es dinero. Sin embargo, la capacidad de los bancos comerciales para crear dinero no es ilimitada. En la cantidad de dinero que pueden crear influye una gama de factores, entre ellos las políticas monetarias, de estabilidad financiera y de regulación del Banco de Inglaterra. Esos límites, y el proceso de creación de dinero más en general, se discuten en detalle en el escrito que acompaña a este artículo.

\section{(III) RESERVAS EN EL BANCO CENTRAL}

Los bancos comerciales necesitan mantener algún efectivo para satisfacer los frecuentes retiros de depósitos y otros flujos. Pero el uso de billetes físicos para realizar el gran volumen de transacciones que hacen entre sí sería sumamente problemático. Por ello se permite que los bancos mantengan un tipo diferente de pagaré del Banco de Inglaterra, conocido como reservas en el banco central, que se muestra en gris claro en la gráfica 2. Las reservas en el Banco de Inglaterra son simplemente un registro electrónico del monto que adeuda el banco central a cada banco individual. 
Las reservas son un medio de cambio útil para los bancos, así como los depósitos lo son para los hogares y compañías. De hecho, se puede pensar que las cuentas de reservas en el banco central cumplen para los bancos comerciales un papel similar al que cumplen las cuentas corrientes para los hogares o firmas. Si un banco desea efectuar un pago a otro -como hacen todos los días, a gran escala, cuando los clientes hacen transacciones- dirá al Banco de Inglaterra que luego ajuste sus saldos de reservas en consecuencia. El Banco de Inglaterra también garantiza que cualquier cantidad de reservas se pueda cambiar por el dinero en efectivo que los bancos comerciales necesiten. Por ejemplo, si muchos hogares quisieran convertir sus depósitos en billetes, los bancos comerciales podrían canjear sus reservas por efectivo para pagar a esos hogares. Como se discutió antes, como emisor de efectivo en circulación, el Banco de Inglaterra puede asegurar que siempre haya suficiente efectivo para satisfacer dicha demanda.

\section{CONCLUSIÓN}

Este artículo muestra qué significa el dinero y los diferentes tipos de dinero que existen en una economía moderna. El dinero es hoy una forma de deuda, pero una clase especial de deuda que es aceptada como medio de cambio en la economía. Y la mayor parte de ese dinero toma la forma de depósitos bancarios, que son creados por los bancos comerciales. El trabajo que acompaña a este artículo, "La creación de dinero en la economía moderna”, describe en más detalle el proceso de creación de dinero por los bancos comerciales.

\section{REFERENCIAS BIBLIOGRÁFICAS}

1. Allen, H. y A. Dent. "Managing the circulation of banknotes", Bank of England Quarterly Bulletin 50, 4, 2010, pp. 302-310.

2. Braudel, F. The wheels of commerce, Berkeley, University of California Press, 1982.

3. Brunner, K. y A. Meltzer. "The uses of money: money in the theory of an exchange economy", American Economic Review 65, 5, 1971, pp. 784-805.

4. Burgess, S. y N. Janssen. "Proposals to modify the measurement of broad money in the United Kingdom: A user consultation", Bank of England Quarterly Bulletin 47, 3, 2007, pp. 402-414.

5. Cairncross, A. "The Bank of England and the British economy", R. Roberts y D. Kynaston, eds., The Bank of England: Money, power and influence 1694-1994, Oxford, Oxford University Press, 1995, pp. 56-82.

6. Doepke, M. y M. Schneider. "Money as a unit of account", NBER Working Paper No. 19537, 2013. 
7. Eichengreen, B. Golden fetters: the gold standard and the Great Depression, Oxford, Oxford University Press, 1992.

8. Farag, M.; D. Harland y D. Nixon. "Bank capital and liquidity", Bank of England Quarterly Bulletin 53, 3, 2013, pp. 201-215.

9. Goodhart, C. "The two concepts of money: Implications for the analysis of optimal currency areas", European Journal of Political Economy 14, 1998, pp. 407-432.

10. King, M. "Trusting in money: From Kirkcaldy to the MPC", 2006, [www.bankofengland.co.uk/archive/Documents/historicpubs/speeches/2006/speech288.pdf].

11. King, R. y C. Plosser. "Money as the mechanism of exchange", Journal of Monetary Economics 17, 1, 1986, pp. 93-115.

12. Kiyotaki, N. y J. Moore. "Evil is the root of all money", Clarendon Lectures (Lecture 1), 2001.

13. Kiyotaki, N. y J. Moore. "Evil is the root of all money", The American Economic Review 92, 2, 2002, pp. 62-66.

14. Kocherlakota, N. "Money is memory", Journal of Economic Theory 81, 2, 1998, pp. 232-251.

15. Manning, M.; E. Nier y J. Schanz, eds. The economics of large-value payment and settlement systems: Theory and policy issues for central banks, Oxford, Oxford University Press, 2009.

16. Menger, C. "On the origins of money", Economic Journal 2, 6, 1892, pp. 239-255.

17. Naqvi, M. y J. Southgate. "Banknotes, local currencies and central bank objectives", Bank of England Quarterly Bulletin 53, 4, 2013, pp. 317-325.

18. Ostroy, J. y R. Starr. "The transactions role of money”, B. Friedman y F. Hahn, eds., Handbook of Monetary Economics, vol. 1, Amsterdam, North-Holland, 1990, pp. 3-62.

19. Radford, R. “The economic organisation of a P.O.W. camp”, Economica 12, 48, 1945, pp. 189-201.

20. Ryan-Collins, J.; T. Greenham, R. Werner y A. Jackson. Where does money come from? A guide to the UK monetary and banking system, Londres, New Economics Foundation, 2011.

21. Sargent, T. "The ends of four big inflations", R. Hall, ed., Inflation: Causes and effects, Chicago y Londres, University of Chicago Press, 1982, pp. 41-97.

22. Smith, A. Lectures on jurisprudence, The Glasgow edition of the Works and Correspondence of Adam Smith, vol. 6: Manuscript B, "Report dated 1766", 1766.

23. Smith, A. An inquiry into the nature and causes of the wealth of nations, The Glasgow edition of the Works and Correspondence of Adam Smith, vol. 2, 1776.

24. Temin, P. Lessons from the Great Depression, Cambridge, Mass. Y Londres, MIT Press, 1989.

25. Wood, J. A bistory of central banking in Great Britain and the United States, Cambridge University Press, 2005.

26. Young, H. Individual strategy and social structure, Princeton y Oxford, Princeton University Press, 1998. 


\section{Cuadro A}

Glosario de los diferentes tipos de dinero y sus diferentes nombres ${ }^{(a)}$

\begin{tabular}{|c|c|c|}
\hline Nombre & Descripción & También conocido como \\
\hline $\begin{array}{l}\text { Depósitos banca- } \\
\text { rios }\end{array}$ & $\begin{array}{l}\text { Tipo de pagaré de un banco } \\
\text { comercial a una persona o empresa }\end{array}$ & $\begin{array}{l}\text { Dinero interno (si no se iguala al } \\
\text { dinero externo en los balances del } \\
\text { banco) }\end{array}$ \\
\hline Base monetaria & $\begin{array}{l}\text { Reservas del banco central + } \\
\text { efectivo en circulación }\end{array}$ & $\begin{array}{l}\text { Base monetaria } \\
\text { Dinero del banco central } \\
\text { Dinero externo (en el Reino } \\
\text { Unido) } \\
\text { Dinero de alto poder } \\
\text { M0 }\end{array}$ \\
\hline $\begin{array}{l}\text { Dinero en sentido } \\
\text { amplio }\end{array}$ & $\begin{array}{l}\text { Efectivo en manos del sector } \\
\text { privado (diferente de los bancos) } \\
\text { + depósitos bancarios (y otras } \\
\text { obligaciones de corto plazo } \\
\text { similares de los bancos comerciales } \\
\text { con el resto del sector privado) }\end{array}$ & $\begin{array}{l}\text { M4 ex (medida titular del dinero } \\
\text { en sentido amplio utilizada por el } \\
\text { Banco de Inglaterra; excluye los } \\
\text { depósitos de ciertas instituciones } \\
\text { financieras, conocidas como inter- } \\
\text { mediarias distintas de sociedades } \\
\text { financieras (IOFC, por sus siglas } \\
\text { en inglés), para proporcionar una } \\
\text { medida de dinero más relevante } \\
\text { del gasto en la economía) } \\
\text { M4 (incluye los depósitos de } \\
\text { IOFC) } \\
\text { M3 (vieja definición que no incluía } \\
\text { los depósitos de sociedades de } \\
\text { construcción) }\end{array}$ \\
\hline $\begin{array}{l}\text { Reservas en el } \\
\text { banco central }\end{array}$ & $\begin{array}{l}\text { Tipo de pagaré del banco central a } \\
\text { un banco comercial }\end{array}$ & \\
\hline Dinero mercancía & $\begin{array}{l}\text { Una mercancía con valor } \\
\text { intrínseco en sí misma que se usa } \\
\text { como dinero porque cumple las } \\
\text { funciones principales, como las } \\
\text { monedas de oro }\end{array}$ & \\
\hline $\begin{array}{l}\text { Efectivo en circula- } \\
\text { ción }\end{array}$ & $\begin{array}{l}\text { Tipo de pagaré (en billetes de } \\
\text { papel o en monedas), en su } \\
\text { mayoría del banco central al } \\
\text { tenedor del billete }\end{array}$ & Billetes y monedas \\
\hline Dinero fiduciario & $\begin{array}{l}\text { Dinero irredimible; es solo una } \\
\text { demanda de pago de más dinero } \\
\text { fiduciario }\end{array}$ & \\
\hline
\end{tabular}

(a) Un recuadro de "La creación de dinero en la economía moderna" explica por qué las diferentes medidas del dinero son útiles para entender la economía. 